Sundler, A.J., Eide, H., Dulmen, S. van, Holmström, I.K. Communicative challenges in the homen care of older persons: a qualitative exploration. Journal of Advanced Nursing: 2016, 72(10),

\begin{tabular}{|l|l|}
$\begin{array}{l}\text { Postprint } \\
\text { Version }\end{array}$ & 1.0 \\
\hline Journal website & $\underline{\text { http://onlinelibrary.wiley.com/doi/10.1111/jan.12996/abstrac t }}$ \\
\hline Pubmed link & $\underline{\text { http://www.ncbi.nlm.nih.gov/pubmed/27144778 }}$ \\
\hline DOI & $10.1111 /$ jan.12996 \\
\hline
\end{tabular}

This is a NIVEL certified Post Print, more info at http://www.nivel.eu

\title{
Communicative challenges in the home care of older persons - a qualitative exploration
}

AnNelie J. Sundler PhD RN Associate Professor ${ }^{1, *}$, Hilde Eide PHD RN Professor ${ }^{2}$, SANDRA VAN DULMEN PHD PROFESSOR ${ }^{2,3,4}$ AND INGER K. HOLMSTRÖM PHD RN PROFESSOR ${ }^{5,6}$

\begin{abstract}
Aim: To explore communicative challenges in encounters between nurse assistants and older persons during home care visits.

Background: The older population is increasing worldwide. Currently, there is a shift in care for older people from institutional care to home care. Providing home care in a person's home involves several challenges, including the complexity of communication.

Design: A descriptive observational design with a qualitative approach was used.

Methods: The data consisted of audio recordings of real-life encounters during home care visits between nurse assistants and older persons, collected in 2014. A hermeneutic phenomenological analysis was conducted.

Results: Communicative challenges were identified: (a) in situations where the older persons had a different view than the nurse assistants on the care task and its content; and (b) when unexpected actions or turns occurred in the communication. Challenges included older person's existential issues, fragility and worries and concerns, which often appeared to be only vaguely expressed and difficult to verbally detect and tackle. This engendered a risk of misinterpretation or ignorance of these challenges.

Conclusion: The findings point to the importance of communication as the key to facilitate person-centred home care. Communication training should focus more on addressing needs and existential issues in older persons. Person-centred home care for older persons needs to be addressed at both an individual and an organizational level.
\end{abstract}


Sundler, A.J., Eide, H., Dulmen, S. van, Holmström, I.K. Communicative challenges in the homecare of older persons: a qualitative exploration. Journal of Advanced Nursing: 2016, 72(10),

\section{Why is this research needed?}

- A shift from institutional to home care for older people can be seen, which increases the demands of home care services.

- Home care for older persons also includes ethical and communicative challenges, whereas nursing staff often focus predominantly on the impaired vision, hearing and cognition abilities when encountering frail older persons.

- This study contributes to our understanding of communicative challenges in encounters with older persons in home care.

\section{What are the key findings?}

- Although home care services are mainly task-oriented, communicative challenges during home care visits arise, including existential issues.

- Unexpected actions or turns in the conversation such as expressions of emotional state or contradicting views of the older persons can be challenging to respond to.

- The needs of the older persons are often only vaguely expressed and therefore difficult to verbally detect and to respond to these issues demands communicative competence.

\section{How should the findings be used to influence policy/practice/research/education?}

- The findings underline the need for understanding and sensitivity to older person's expressions as being central to person-centred communication.

- Education and training for home care providers should focus more on addressing existential issues of older persons and person-centred communication.

- The communication competency of care providers is important to facilitate person-centred home care and needs to be acknowledged both on an individual and an organizational level.

\section{INTRODUCTION}

The older population is increasing worldwide and as a result the demand for home care is rapidly increasing, in addition to changes in healthcare policies and a desire to remain at home (Rioux 2005). Consequently, a shift from institutional to home care of the older persons can be seen (Thomé et al. 2003) and the home has become an arena for both professional and informal care. In this study, home care refers to the care given by professionals in the homes of older persons, covering a wide range of activities, from preventive to end-of-life care (Thomé et al. 2003). The policy, organization and availability of home care services differ markedly both within and between countries (Genet et al. 2011). Home care is usually carried out by a nursing staff with different levels of education and training, some even lack formal healthcare training (Bing-Jonsson et al. 2016). As expected, the actual formal educational level is related to higher scoring in competence (Bing-Jonsson et al. 2016). However, still little is known about the communication competencies needed 
Sundler, A.J., Eide, H., Dulmen, S. van, Holmström, I.K. Communicative challenges in the homen care of older persons: a qualitative exploration. Journal of Advanced Nursing: 2016, 72(10), 2435-2444

by professionals in home care. To further understand the nature of the communication with older persons in home care and of potentially challenging situations, this study was conducted.

\section{Background}

Little is known on how to facilitate person-centred and effective communication in home care. The overall objectives of home care are to improve quality of life and maintain independence by actions and assessments of the persons' needs that make it possible to remain living at home (Thomé et al. 2003). The home may not only designate a dwelling but also represent identity, security and privacy (Williams 2002). Thus, the home represents ideas for the individual that may influence caregiving. As in all caregiving, interaction and communication are important. It is widely accepted that communication is crucial in nurse-patient interactions (CarisVerhallen et al. 1997). Barriers to interaction and communication in encounters with older persons, however, exist. In such encounters, impaired vision, hearing or cognitive functions can hamper the communication. Additionally, communication with older persons can be complicated because of different agendas or a generation gap (Caris-Verhallen et al. 1997). One might enter a process of gerotranscendence, which is characterized by a shift in metaperspective from a materialistic and rational worldview to a redefinition of self and relationships with others (Wadensten \& Carlsson 2003). This process also has an impact on nurse-patient interaction. Wellfunctioning communication can positively contribute to the health of the patient and communication might lessen anxiety and create a trusting relationship (Street et al. 2009).

The care of older persons aims to improve quality of life and health. Health and wellbeing need to be understood as related to an older person's everyday life and an individual's situation (Dahlberg \& Segesten 2010). In everyday life, the home is important to the older person's identity and integrity (Gillsjö et al. 2011). Receiving home care may however be a dual experience of both independence and dependence. Even when home care is the patient's own choice, it involves an adaptation to the routines of the care providers. It is ambiguous to accept being in need of care while simultaneously maintaining independence and privacy (Holmberg et al. 2012).

Nurses also describe home care services as ambiguous; in the same time as they are guests in a home, they must handle their professional role and the power imbalance that might occur. In their communication with the patients, nurses need to balance between being more or less authoritarian. When they talk about the patients it indicates having power over them, thus representing an asymmetric relationship. In addition, the language used expresses different values and norms (Oresland et al. 2008).

Consequently, home care can be complex. It embraces care in a constant motion, requiring adjustments to changing circumstances. It may also hold ethical issues which are invisible (Oresland et al. 2011). In addition, the care may be influenced by emotional aspects; professionals experienced a need to understand and balance both frustrating and satisfying experiences causing confusion and distress (Devik et al. 2013). Home care providers may also face conflicts of interest between an older person's right to self-determination and external demands (Breitholtz et al. 2013). Thus, providing care in a person's home involves several challenges influencing caregiving and communication. 
Sundler, A.J., Eide, H., Dulmen, S. van, Holmström, I.K. Communicative challenges in the homen care of older persons: a qualitative exploration. Journal of Advanced Nursing: 2016, 72(10), 2435-2444

\section{Person-centred care and person-centred communication}

High-quality care is closely linked to person-centred care and evidence for the advantages of such care is growing (Ekman et al. 2012, Edvardsson et al. 2014, Sjögren et al. 2015). The main idea of person-centred care is to treat patients as persons (Entwistle \& Watt 2013). Person-centred care is defined as 'an approach to practice that is established through the formation and fostering of therapeutic relationships between all care providers, patients and others significant to them' (McCormack et al. 2011). The approach reflects humanistic values of respect for persons and individual right to self-determination, with mutual respect and understanding (McCormack et al. 2010, 2011). Person-centred care includes comforting communication and empathy, and supporting the persons' capabilities for autonomy (Entwistle \& Watt 2013). However, nurse-patient communication is more than only a transmission of information. It includes the acknowledgement and confirmation of emotions (McCabe 2004). Inability to be present in the caring encounter may expose older persons to unnecessary suffering, increasing their feelings of insecurity and loneliness (Svanström et al. 2013). Consequently, home care service seems to unfold caregiving in a complex environment laden with caring and communicative challenges. Earlier research has reported on the complexity of entering the home of the patients, whereas less attention has been paid to the interaction and communicative practices between nurse assistants and older persons in home care services.

\section{THE STUDY}

\section{Aim}

The aim of the study was to explore communicative challenges in encounters between nurse assistants and older persons during home care visits.

\section{Design}

A descriptive observational design with a qualitative approach was used in this study, as part of the international research program COMHOME (Hafskjold et al. 2015) on person-centred communication with older persons receiving health care. Audio recordings from home care visits were gathered during 2014 and analysed with a hermeneutical phenomenological approach (van Manen 1997).

\section{Sample}

The data consisted of 100 audio recordings of real-life encounters between 19 nurse assistants and 43 older persons in home care. In Sweden, where this study was carried out, home care services are mostly carried out by nurse assistants, qualified through a degree from upper secondary school. The participating 19 nurse assistants were aged between 22 and 63 years, with a mean age of 42 years. Eleven nurse assistants were women and eight were men. They had worked between 3 months and 36 years at the present workplace (mean $=18$ years). The participating 43 older persons were aged between 66 and 103 years, with a mean age of 87 years. Of those, 28 were women and 15 were men. Most of them were living alone $(n=35)$. They were helped with tasks such as shopping, preparing meals, cleaning, taking medication and personal hygiene; some also received assistance to the lavatory. 
Sundler, A.J., Eide, H., Dulmen, S. van, Holmström, I.K. Communicative challenges in the homen care of older persons: a qualitative exploration. Journal of Advanced Nursing: 2016, 72(10), 2435-2444

\section{Data collection}

Data were collected during autumn 2014 and consisted of recordings between 186 minutes (mean $=16$ minutes). Participating nurse assistants were given instructions face to face by one of the researchers on how to prepare for and to do the recordings. They were asked to invite all of their patients over the age of 65 years and able to give informed consent. Many patients were excluded due to cognitive impairment. After having obtained informed consent, the recording started. The nurse assistants were provided with the recording equipment, placed on their upper arm, to minimally interrupt the work procedures. The audio recordings started when the nurse assistant arrived at the home of the older person and ended while leaving. The data gathering was complex, as there were several nurse assistants involved with helping the researcher recruit older persons and making the audio recordings.

\section{Ethical considerations}

This study was approved by the Regional ethics committee in Uppsala, Sweden (Dnr 2014/018). The study conforms to the Declaration of Helsinki (World Medical Association 2008) and complies with the ethical standards for research. Written and verbal information discussing the nature, purpose and methods of the study were given to the nurse assistants and the older persons. Written informed consent was obtained from both nurse assistants and older persons, who were made aware of their right to withdraw at any time without consequences. They were guaranteed confidentiality and were informed that participation was voluntary.

\section{Data analysis}

To gain a deeper understanding of communicative challenges in the data, a qualitative analysis with a hermeneutic phenomenological approach was performed (van Manen 1997). The goal of the analysis was to grasp the meaning of communicative challenges. During the analysis, such challenges were interpreted in specific situations standing out from the normal communication. The approach allowed the researchers to make interpretations. This demands holding back the researchers' pre-understanding or pre-conceptions, i.e. interpretations made were compared with descriptions of the situations and the actual audio recorded situation for rigour. The researchers' pre-understanding comprised knowledge on healthcare communication and what constitutes good communication in caring encounters. We strived to hold back negative influences of our pre-understanding and to focus on what the data yielded. The approach does not have a step-by-step method. Rather, the analysis involves a dynamic interplay to illuminate details and aspects of the data. The analysis requires reading and reflective writing while listening to the conversations, followed by interpretations to uncover and cluster themes. Considerations of parts and all of the data need to be made (van Manen 1997, 2006). Authors AJS and IKH are well experienced in this method.

The analysis started with listening to all recordings to obtain an understanding of the data. Subsequently, communicative challenges that stood out and were deemed to have a special significance were sought. Sequences in the audio recordings with communication challenges were repeatedly listened to and described in text. The analysis continued with a search for meanings, which were compared for similarities and differences. This phase revealed essential elements in the interaction and communication. Furthermore, the analysis involved an iterative movement between the whole and the parts of the data, going back to the recordings during the analysis. 
Sundler, A.J., Eide, H., Dulmen, S. van, Holmström, I.K. Communicative challenges in the homen care of older persons: a qualitative exploration. Journal of Advanced Nursing: 2016, 72(10), 2435-2444

Finally, the analysis resulted in four themes, illustrated with case examples and quotes representative for the findings. In the quotes abbreviations are used as follows; $\mathrm{W}$ is used for women patient, $\mathrm{M}$ for male patient and NA for nurse assistants. The themes are not mutually exclusive and to some extent overlapping. The analysis was mainly performed by the author AJS and validated by the author IKH, who followed every step in the analysis, read and gave comments and also listened to the audio recordings. All authors read and commented on the final version of the analysis to ensure the rigour of the results and themes described.

\section{Rigour}

Four widely used criteria in the discussion of trustworthiness of qualitative studies are credibility, dependability, confirmability and transferability (Guba \& Lincoln 1989). The total sample consisted of a relatively large number of audio recordings to obtain a representative sample of home care visits. In striving for credibility, the procedures for sample, data collection and analysis were presented as thoroughly as possible. The results were illustrated with case examples and quotes to show that interpretations and descriptions made were grounded in the data to assure confirmability. To uphold the criterion of dependability, the research process was described in detail to make it possible for the reader to agree with and understand the logic of the findings.

\section{Findings}

Communicative challenges during home care visits occurred when the nurse assistants did not know what to expect or how to respond to the older person's expression. In such a situation, their communicative competence was challenged. Situations when the older persons expressed a different view than the nurse assistants about the home care services or when something unexpected followed were difficult to handle. The communication during the present home care encounters was mainly task-oriented. However, the older persons also expressed existential issues of importance about the experiences of becoming old and approaching the end of life and individual needs, and worries and concerns. These expressions were sometimes vague and difficult to verbally detect. Expressions of importance could occur in any stage during the visit. Small nuances that may, at first, seem irrelevant could have an underlying significant meaning. The findings are described in four themes:

- Handling existential issues

- Facing older persons' fragility and dependence

- Encountering worries and concerns related to daily life

- Encountering different views and disappointments

\section{Handling existential issues}

It was clear that the older persons were in a different phase of life than the nurse assistants. Experiences and concerns related to becoming old and reaching the end of life were expressed. Existential issues were seldom on the agenda for the visits; such expressions were commonly unexpected, without obvious answers and seemed difficult to respond to.

A home care visit with an old man can exemplify how unexpected existential issues may arise. The nurse assistant helped him with his medications and breakfast. They were quite silent while the tasks were performed. At the end of the visit, the nurse 
Sundler, A.J., Eide, H., Dulmen, S. van, Holmström, I.K. Communicative challenges in the homecare of older persons: a qualitative exploration. Journal of Advanced Nursing: 2016, 72(10),

assistant asked him if he visited an event the day before. He answered that he was too tired, feeling too weak. The nurse assistant confirmed his experience with a short 'Yes'. After some silence, he almost whispered, 'It's finished with me ... soon it will be over with the old man'. The nurse assistant tried to cheer him up, but he disagreed. After being silent, he said that he noticed that his body was getting old and weak. For the old man, it was obvious that he was approaching the end of his life. The nurse assistants' handling of situations with existential issues differed. In some situations, they failed to notice them. In others, they were pliable and followed the issues in a dialogue by asking questions, listening or confirming. For instance, during a visit when a nurse assistant encountered an old woman expressing that she feels totally exhausted. The nurse assistant listened to her experiences and told her to take care of herself. The women said that it is awkward for her to get old and that she feels weak and fragile, saying: 'At the end, it will become dark. But I am old, you know'. The nurse assistant responded with sensitivity and tried to reassure her. He told her that she is strong and that she, after all, is managing her suffering fine. With his sensitivity to her existential worries, he seemed to calm her.

Confronting existential issues can be challenging, especially when unprepared. Situations were also found where the nurse assistants were missing opportunities to confirm or explore the expressions of existential issues. A meaningful way to respond positively was to show compassion and give hope. For example, the nurse assistant was encouraging the woman as mentioned above. In addition, existential issues could be vaguely expressed verbally, requiring attentiveness and active listening to be noticed.

\section{Facing an older persons' fragility and dependence}

During the visits, the nurse assistants' encountered older persons' fragility and dependence because of ageing or diseases. They encountered difficulties such as pain, vision impairments or dizziness. Ageing and illness leave traces of bodily weakness that could influence the communication negatively. It also made the relationship imbalanced. For instance, a nurse assistant visited an old woman, who lives with her husband in their apartment, to help her with her medication. During the visit, the nurse assistant asked how she felt and she answered that it was a bad day: W

NA

Yes, It's bad.

W

So you say?

Yes.

NA

How is it then, you think, how do you feel?

$\mathrm{W}$

NA

My vision is bad...

That's what bothers you?

W

Yes, yes, it comes and goes, when I'm tired.' 
Sundler, A.J., Eide, H., Dulmen, S. van, Holmström, I.K. Communicative challenges in the homen care of older persons: a qualitative exploration. Journal of Advanced Nursing: 2016, 72(10),

By asking questions, the nurse assistant explored her experiences and they continued talking about how she felt. During the talk, they were interrupted by the nurse assistant's cell phone. Thereafter, the woman said that she was dizzy and repeated that her vision was impaired. The nurse assistant answered that she should rest and take care of herself and emphasized that she can call for help, if needed. 'Yes, I just heard that, that they [meaning other patients] called for you', she answered. They discussed the fact that there are many old people in need of help and that the nurse assistant has a lot to do. 'They want your help', the woman repeats 'So do I, that's the worst thing,' she said with resignation. The woman did not want to be a burden, yet she was still worried. It seems she wanted to be assured of getting help when needed. Bodily weakness caused by ageing or diseases can be inconvenient for older persons. For instance, a man said: 'I have started to notice it on my body; I have that for a long time now'. Ageing and dependency influenced the interaction and was sometimes difficult to respond to in a positive way.

\section{Encountering worries and concerns related to daily life}

The nurse assistants encountered various worries and concerns important in everyday life of the older persons and there was a need to address things that matter to older persons. However, some of these matters were difficult to handle or solve because they did not contain any obvious problem, but were at risk of becoming one. This is illustrated by an old woman who was worried about her legs. Before getting help from the nurse assistant with bandaging her legs, she said that her legs had started to hurt the day before. She was really concerned whether there had been any ulcers or if something was wrong with her legs. When winding off the bandage, her legs were fine and the nurse assistant could not give any reasonable explanation of what had caused the pain. Still, the woman repeats her worries several times. The nurse assistant confirmed her worries and she appeared confident when being reassured that her legs looked good. Although being unable to explain the pain, the nurse assistant interacted and responded to her worries.

Different responses were found to other worries and concerns, regardless of whether these problems could be solved or not. This is also illustrated in the following example that started with an old woman ironically stating:
'W
NA
It's just as fun every day [really meaning that the day is awful].
W
Yes, really fun every day [the care provider responds ironically].
NA
Yes, awful.
$\mathrm{W}$
Have you slept well?
Quite well, but then the doorbell rang again. I don't know what it is'.

The conversation turned into the woman telling about her doorbell which has been ringing for several nights. When she opened the door, no one was there, which worried her. The nurse assistant responded that he did not know the cause, even 
Sundler, A.J., Eide, H., Dulmen, S. van, Holmström, I.K. Communicative challenges in the homecare of older persons: a qualitative exploration. Journal of Advanced Nursing: 2016, 72(10),

though he did not think anyone could come to her door at night. He confirmed her experience without distrusting her, even though he could not solve the problem. By capturing that which was important and by being attentive, he was supportive. At other times, the nurse assistants tried to lighten the situation or handle it with a sense of humour, which can be difficult and sometimes disconfirming. When the nurse assistants were sensitive and responded to worries and concerns being distrustful, this seemed to be most helpful for the older persons.

\section{Encountering different views and disappointments}

Even if the agenda for home care visits is mostly fixed and task oriented, the encounter and what happens during the visits are not previously defined. At times, the views of the nurse assistant and older persons differed. Depending on the situation, communicative challenges were handled in various ways. In some situations, the dialogue took an unexpected direction. In other situations, there were difficulties to establish a mutual dialogue, which complicated the conversation and made the encounter ambiguous. For example, a nurse assistant who was visiting an old man in the morning to help him with the treatment of contracture needed to rethink her plans for the visit and change actions. The visit was aimed to assist him getting in the wheelchair for exercises. However, he refused to do the exercises with several clear 'No' responses because he already had done some walking exercises that morning. After some friendly but determined requests, the nurse assistant had to submit to what he wanted. The visit became different than intended.

Older persons do not necessarily have the same agenda as the nurse assistants. In accordance with the goals of the visit, the nurse assistants commonly focused on the tasks at hand. The system and structure of the home care services influenced on both nurse assistants and older persons. At times, different agendas become troublesome and challenging. Encountering someone being angry, disappointed or dissatisfied was not always easy, as described in the following example. During a visit to an older couple, a nurse assistant encountered their feelings of disappointment. The husband is dissatisfied and told about how they missed a party the day before. This inconvenience was caused by the nurse assistant being delayed and his wife felt sleepy at that time. He expressed that he was displeased and felt overlooked, not being able to fulfil their plans. Although he remained gentle and humble during the visit, he expressed his major disappointment. Several times, he told about the delay:

$\mathrm{M}$

NA

They arrived too late and had to hurry.

What a shame.

M

NA

They arrived too late and had to hurry.

Yes...'

The nurse assistant apologized for what happened but could not compensate for it. Still, the man remains dissatisfied and not confirmed. Challenging situations put demands on the nurse assistants to be sensitive and open to what comes up while performing the required tasks. 
Sundler, A.J., Eide, H., Dulmen, S. van, Holmström, I.K. Communicative challenges in the homen care of older persons: a qualitative exploration. Journal of Advanced Nursing: 2016, 72(10), 2435-2444

\section{DISCUSSION}

This study has provided insight into the communicative challenges encountered by nurse assistants during recorded home care visits to older persons. These findings can be summarized as: 'Handling existential issues'; 'Facing older persons fragility and dependence'; 'Encountering worries and concerns related to daily life'; and 'Encountering different views and disappointments'.

In this study, a need to talk about existential issues was identified. However, the views and needs of older persons can be vaguely expressed and difficult to verbally detect. Overall, this made the older persons' experiences sometimes challenging to handle, without clear answers. A further challenge was that these encounters and the communication was mostly task oriented, with limited time to talk things through. Moreover, the communication can be impeded by a generation gap (Caris-Verhallen et al. 1997), which seemed to be the case also in this study. Being old means being in a phase of life, when existential questions come to a fore (Jewell 2014). Human development is a process extending also into old age and older people may need support in these processes (Wadensten \& Carlsson 2003). This could mean to facilitate talks about existential issues. Conversations on ageing and death can, however, be difficult to handle. Similar to our findings, Wadensten et al. (2007) described difficulties for nursing staff to address discussions about death in the care of older people. This is also consistent with the findings from Sheldon et al. (2006), who found that conversations about approaching end of life and conversations which were emotionally laden were among the most difficult for nurses to cope with. To pay attention to the view of the older person demanded the nurse assistants in this study to be pliable and sensitive to what came up and what happened, while having tasks to attend to and a strict time schedule to comply with. It seems clear that care providers could benefit from training on how to better communicate on existential issues; emotionally laden conversations require advanced communication skills as concluded also by Sheldon et al. (2006). Attending behaviours in communication is valued by patients (McCabe 2004) and such behaviours involve giving time and presence. Disadvantages can be experienced when care providers are unable to see the patients' needs or to be present in the encounter (Svanström et al. 2013). To confirm and approach the older person as a person, while performing caring tasks, seems to be at the core of person-centred communication in home care. In contrast, task-oriented communication is more focused on care providers' work tasks than on personal communication with patients (McCabe 2004), which was also found in our study. Park and Song (2005) point to the importance of understanding communication barriers from the perspective of older patients. While conducted in a hospital setting, the older patients in their study reported being hesitant to interrupt nurses' work as one of the major communication obstacles. There are reasons to believe that this also holds true in task-oriented home care. It seems important to give space and encourage older persons to voice their concerns, which requires being attentive and listening. This could be achieved by giving time to respond (O'Hagan et al. 2013). However, nurses tend to see relationship-building communication as time consuming (Chan et al. 2011). Thus, more awareness is needed on communicative competences essential in person-centred care.

Good communication is important in the care of older persons to support healing processes (Street et al. 2009). Today, the need to practise person-centred care is evident (Capezuti \& Hamers 2013). This is also consistent with compassionate 
Sundler, A.J., Eide, H., Dulmen, S. van, Holmström, I.K. Communicative challenges in the homecare of older persons: a qualitative exploration. Journal of Advanced Nursing: 2016, 72(10), 2435-2444

relationship-centred care as a framework developed for the care of older persons (Dewar \& Nolan 2013). In this study, relationship building was dependent on the communication and relationship building can be hampered in communicative challenging situations. McCabe (2004) argues that the healthcare organizations do not value the importance of nurses using a patient-centred approach when communicating with patients. The agenda for home care services needs to include caring conversations with awareness of existential issues in old ages. However, talking about death is demanding for nurses and such talks are sometimes actively avoided (Wadensten et al. 2007). If home care organizations want to ensure highquality nursing care, person-centred care and communication should be put at the forefront. Even though caring conversations are acknowledged for being important in patient-centred care for older persons (Dewar \& Nolan 2013), still little attention has been paid on the actual communication and on how to communicate in a personcentred way. This study points to a need for education and training in person-centred communication, which could contribute to increased quality of care. Kasén et al. (2008) stated that a rigid care organization with an unreflective attitude of care providers can create suffering when objectifying the patient. In addition to it, the training reflection in groups can be used to enhance nurses' capability to meet the older persons' needs (Wadensten et al. 2007). Developing person-centred care is not a one-person task. Rather, it requires commitment from teams. It is not about momentary changes but instead about a shift in cultures (McCormack et al. 2011). Thus, a person-centred approach is important both on an organizational level and in the individual encounter. To establish high-quality care, both processes and structural aspects of care need attention (Donabedian 1988). Altogether, this points to a need for training of nurses in person-centred communication and a care organization allowing time for conversations and relationship-building.

\section{Study limitations}

The data were limited to the audio recordings and solely the verbal communication and paraverbal communication were analysed. Hence, no follow-up questions or further descriptions of the participants' experiences were retrieved. Stimulated recalls could be used in future studies. Regardless, the recordings used in the study have given a picture of home care visits as they occur in real life. Non-verbal communication such as eye contact, stance and touch was no captured in the present audio recording. These are, however, well-known aspects of communication (O'Hagan et al. 2013), but needs video recordings or participant observations to be captured.

The analysis was performed by researchers with a broad experience in qualitative and/or communication research in nursing and health care. During the analysis, the researchers discussed the findings to ensure the rigour and trustworthiness of the results and themes described. Moreover, research ethics were discussed throughout the process. In this study, audio recordings were used for practical reasons. Their use was mainly based on ethical considerations of the intrusiveness of using video recording in a person's own home, including the awareness of the vulnerable position of older persons dependent on help in their home and to respect their integrity. The study was limited to a specific Swedish context, which may impair transferability to other contexts or countries. However, a relatively large number of audio recordings were gathered and the methodological approach used was found to 
Sundler, A.J., Eide, H., Dulmen, S. van, Holmström, I.K. Communicative challenges in the homecare of older persons: a qualitative exploration. Journal of Advanced Nursing: 2016, 72(10), 2435-2444

be well suited. An issue for future research would be to develop educational interventions for care providers to improve person-centred communication skills.

\section{CONCLUSIONS}

The understanding and sensitivity to older person's expressions during home care visits are important to enhance person-centred care. More focus is needed on communication as a core competency in person-centred and compassionate care. Policies may be required for person-centred communication and guidelines outlined to support professionals' communicative competence. Further research is necessary on how to improve communication skills of care professionals in this setting. Evidence-based education and training on person-centred communication with older persons need to be developed. Such education should focus more on addressing existential issues, person-centred care and prerequisites for communication both on an individual and an organizational level.

\section{ACKNOWLEDGEMENTS}

We thank all study participants for their contribution to this project.

\section{FUNDING}

This work was supported by The Research Council of Norway, grant no. 226537 (PraksisVEL).

\section{CONFLICT OF INTEREST}

No conflict of interest has been declared by the authors.

\section{AUTHOR CONTRIBUTIONS}

All authors have agreed on the final version and meet at least one of the following criteria [recommended by the ICMJE (http://www.icmje.org/recommendations/)]:

- substantial contributions to conception and design, acquisition of data, or analysis and interpretation of data;

- drafting the article or revising it critically for important intellectual content.

\section{REFERENCES}

Bing-Jonsson P.C., Hofoss D., Kirkevold M., Bjørk I.T. \& Foss C. (2016) Sufficient competence in community elderly care? Results from a competence measurement of nursing staff. BMC Nursing 15, 5. doi:10.1186/s12912-016-0124-z.eCollection.2016.

Breitholtz A., Snellman I. \& Fagerberg I. (2013) Carers' ambivalence in conflict situations with older persons. Nursing Ethics 20(2), 226-237.

Capezuti E. \& Hamers J.P. (2013) Perspectives on how to improve the nursing care of older adults. International Journal of Nursing Studies 50(9), 1153-1155.

Caris-Verhallen W.M., Kerkstra A. \& Bensing J.M. (1997) The role of communication in nursing care for elderly people: a review of the literature. Journal of Advanced Nursing 25(5), 915-933.

Chan E.A., Jones A., Fung S. \& Wu S.C. (2011) Nurses' perceptions of time availability in patient communication in Hong Kong. Journal of Clinical Nursing 21(7-8), 1168-1177.

Dahlberg K. \& Segesten K. (2010) Health and Caring in Theory and Practice [Hälsa och vårdande i teori och praxis]. Natur och kultur, Stockholm, Sweden. 
Sundler, A.J., Eide, H., Dulmen, S. van, Holmström, I.K. Communicative challenges in the homecare of older persons: a qualitative exploration. Journal of Advanced Nursing: 2016, 72(10), 2435-2444

Devik S., Enmarker I. \& Hellzen O. (2013) When expressions make impressions—Nurses' narratives about meeting severely ill patients in home nursing care: a phenomenologicalhermeneutic approach to understanding. International Journal of Qualitative Studies on Health and Well-being 8, doi:10.3402/qhw.v8i0.21880.

Dewar B. \& Nolan M. (2013) Caring about caring: developing a model to implement compassionate relationship centred care in an older people care setting. International Journal of Nursing Studies 50(9), 1247-1258.

Donabedian A. (1988) The quality of care: how can it be assessed? JAMA 260(12), 17431748.

Edvardsson D., Petersson L., Sjogren K., Lindkvist M. \& Sandman P.O. (2014) Everyday activities for people with dementia in residential aged care: associations with personcentredness and quality of life. International Journal of Older People Nursing 9(4), 169176.

Ekman I., Wolf A., Olsson L.E., Taft C., Dudas K., Schaufelberger M. \& Swedberg K. (2012) Effects of person-centred care in patients with chronic heart failure: the PCC-HF study. European Heart Journal 33(9), 1112-1121.

Entwistle V. \& Watt I.S. (2013) Treating patients as persons: a capabilities approach to support delivery of person-centered care. The American Journal of Bioethics 13(8), 29-39.

Genet N., Boerma W.G., Kringos D.S., Bouman A., Francke A.L., Fagerström C., Melchiorre M.G., Greco C. \& Devillé W. (2011) Home care in Europe: a systematic literature review. BMC Health Services Research 11, 207. doi:10.1186/1472-6963-11-207.

Gillsjö C., Schwartz-Barcott D. \& Von Post I. (2011) Home: the place the older adult cannot imagine living without. BMC Geriatrics 11, 10. doi:10.1186/1471-2318-11-10.

Guba E. \& Lincoln Y.S. (1989) Fourth Generation Evaluation. Sage, Newbury Park, CA. Hafskjold L., Sundler A.J., Holmström I.K., Sundling V., Van Dulmen S. \& Eide H. (2015) A cross-sectional study on person-centred communication in the care of older people: the COMHOME study protocol. BMJ Open 5(4), e007864. doi:10.1136/bmjopen-2015-007864.

Holmberg M., Valmari G. \& Lundgren S.M. (2012) Patients' experiences of homecare nursing: balancing the duality between obtaining care and to maintain dignity and selfdetermination. Scandinavian Journal of Caring Science 26(4), 705-712.

Jewell A. (2014) Tornstam's notion of gerotranscendence: re-examining and questioning the theory. Journal of Aging Studies 112-20, doi:10.1016/j.jaging.2014.04.003.

Kasén A., Nordman T., Lindholm T. \& Eriksson K. (2008) When the patient suffers from care - carers portrayal of patients' care suffering [Då patienten lider av vården - vårdares gestaltning av patientens vårdlidande]. Vård i Norden 88(28), 4-8.

van Manen M. (1997) Researching Lived Experience: Human Science for An Action Sensitive Pedagogy, 2nd edn. Althouse Press, Ontario.

van Manen M. (2006) Writing qualitatively, or the demands of writing. Qualitative Health Research 16(5), 713-722.

McCabe C. (2004) Nurse-patient communication: an exploration of patients' experiences. Journal of Clinical Nursing 13(1), 41-49.

McCormack B., Dewing J., Breslin E., Coyne-Nevin A., Kennedy K., Manning M., Tobin C. \& Slater P. (2010) Developing person-centred practice: nursing outcomes arising from changes to the care environment in residential settings for older people. International Journal of Older People Nursing 5(2), 93-107.

McCormack B., Dewing J. \& McCance T. (2011) Developing person-centred care: addressing contextual challenges through practice development. The Online Journal of Issues in Nursing 16(2), 3.

O'Hagan S., Manias E., Elder C., Pill J., Woodward-Kron R., McNamara T., Webb G. \& McColl G. (2013) What counts as effective communication in nursing? Evidence from nurse educators' and clinicians' feedback on nurse interactions with simulated patients. Journal of Advanced Nursing 70(6), 1344-1356.

Oresland S., Määttä S., Norberg A., Jörgensen M.W. \& Lützén K. (2008) Nurses as guests or professionals in home health care. Nursing Ethics 15(3), 371-383.

Oresland S., Määttä S., Norberg A. \& Lützén K. (2011) Home-based nursing: an endless journey. Nursing Ethics 18(3), 408-417.

Park E.-K. \& Song M. (2005) Communication barriers perceived by older patients and nurses. International Journal of Nursing Studies 42(2), 159-166. 
Sundler, A.J., Eide, H., Dulmen, S. van, Holmström, I.K. Communicative challenges in the homen care of older persons: a qualitative exploration. Journal of Advanced Nursing: 2016, 72(10),

2435-2444

Rioux L. (2005) The well-being of aging people living in their own homes. Journal of Environmental Psychology 25(2), 231-243.

Sheldon L.K., Barrett R. \& Ellington L. (2006) Difficult communication in nursing. Journal of Nursing Scholarship 38(2), 141-147.

Sjögren K., Lindkvist M., Sandman P.O., Zingmark K. \& Edvardsson D. (2015) To what extent is the work environment of staff related to person-centred care? A cross-sectional study of residential aged care. Journal of Clinical Nursing 9-10, 1310-1319. doi:10.1111/jocn.12734.

Street R.J., Makoul G., Arora N.K., Epstein R.M., Arora N.K. \& Epstein R.M. (2009) How does communication heal? Pathways linking clinician-patient communication to health outcomes. Patient Education and Counseling 74(3), 295-301.

Svanström R., Sundler A.J., Berglund M. \& Westin L. (2013) Suffering caused by care elderly patients' experiences in community care. International Journal of Qualitative Studies on Health and Well-being 8, 20603. doi:10.3402/qhw.v8i0.20603.

Thomé B., Dykes A.K. \& Hallberg I.R. (2003) Home care with regard to definition, care recipients, content and outcome: systematic literature review. Journal of Clinical Nursing 12(6), 860-872.

Wadensten B. \& Carlsson M. (2003) Theory driven guidelines for practical care of older people, based on the theory of gerotranscendece. Journal of Advanced Nursing 41, 462 470.

Wadensten B., Condén E., Wahlund L. \& Murray K. (2007) How nursing home staff deal with residents who talk about death. International Journal of Older People Nursing 2(4), 214219.

Williams A. (2002) Changing geographies of care: employing the concept of therapeutic landscapes as a framework in examining home space. Social Science \& Medicine 55(1), $141-154$.

World Medical Association. (2008) Declaration of Helsinki Ethical Principles for Medical Research Involving Human Subjects. In 59th WMA General Assembly, Seoul, October 2008. World Medical Association, DoH. 